\title{
Chemical Constituents from the Infusion of Zollernia ilicifolia Vog. and Comparison with Maytenus Species
}

\author{
Roberta Gomes Coelho ${ }^{\mathrm{a}}$, Luiz Claudio Di Stasi ${ }^{\mathrm{b}}$, and Wagner Vilegas ${ }^{\mathrm{a}^{*}}$ \\ a Universidade Estadual Paulista, Instituto de Química de Araraquara, C. Postal 355, \\ 14801-970, Araraquara, SP, Brazil. Fax: (+55)(16)2227932. E-mail: vilegasw@iq.unesp.br \\ b Universidade Estadual Paulista, Departamento de Farmacologia, Instituto de Biociências, \\ 18618-000, Botucatu, SP, Brazil \\ * Author for correspondence and reprint requests \\ Z. Naturforsch. 58c, 47-52 (2003); received July 18/August 20, 2002
}

The new flavonoid glycoside kaempferol-3-O- $\alpha$-L-rhamnopyranosyl $(1 \rightarrow 2)-\mathrm{O}-[\alpha$-L-rhamnopyranosyl $(1 \rightarrow 6)]-O-\beta$-D-galactopyranoside-7-O- $\alpha$-L-rhamnopyranoside was isolated together with $(S)$-zierin from the leaves of Zollernia ilicifolia (Fabaceae), a medicinal plant used as analgesic and antiulcerogenic effects in Brazilian Tropical Atlantic Rain Forest. The structures were established on the basis of ${ }^{1} \mathrm{H},{ }^{13} \mathrm{C}$ NMR and 2D NMR (COSY, HMBC, HMQC), UV, MS and IV spectra. The infusion of Zollernia ilicifolia was qualitatively compared to the infusion of the espinheiras-santas (Maytenus aquifolium and Maytenus ilicifolia) by HPLCDAD.

Key words: Zollernia ilicifolia, Flavonol Glycoside, Maytenus Species

\section{Introduction}

In Brazil many plants are used in folk medicine as aqueous infusions because of their biological activities. This is the case of Maytenus ilicifolia and M. aquifolium (Celastraceae), whose leaves are widely employed and have shown anti-ulcer properties (Souza-Formigoni et al., 1991). Because of the similar phenotypic characteristics, some plant species were incorporated as medicines by traditional communities of Brazilian Tropical Atlantic Forest (Di Stasi et al., 2002). Some of these species have been commercialized with the same traditional uses of the true Maytenus species (Vilegas et al., 1995; Sanommiya et al., 1998). One of these species is Zollernia ilicifolia (Fabaceae), which is also popularly known as "espinheira-santa".

In a recent comparative study, Gonzalez et al. (2001) investigated the analgesic and antiulcerogenic effects of $70 \%$ methanolic extract of the leaves of Z. ilicifolia, Sorocea bomplandii and Maytenus aquifolium. A methanolic extract of Zollernia ilicifolia showed analgesic and antiulcerogenic effects on gastric lesions induced by indomethacin/bethanechol in mices. In the same study, Gonzalez et al. (2001) show that leaves of Zollernia ilicifolia reacted positively for catechins, fixed acids, flavones, flavonols, saponins, steroids, tannins, triterpenoids and xanthones, but no chemical compounds was isolated. Another reports found in the literature for plants from this genus deals with the presence of flavonoids, isoflavonoids and chalcones from the wood of Zollernia paraensis (Ferrari et al., 1983, 1984).

Therefore, we decided to chemically investigate the leaves of $Z$. ilicifolia because chemical information is important not only for understanding the folk utilization but also for the validation of compounds as markers for the assessment of the infusion of different Brazilian 'espinheira-santas' In this paper we report the isolation and structure elucidation of a new flavonol tetrasaccharide from the leaves of Zollernia ilicifolia by HPLC-DAD (high performance liquid chromatography coupled to diode array detector) analyses.

\section{Materials and Methods}

\section{Biological material}

The plant material was collected in December in the Intervales State Park, Saibadela, Sete Barras, Vale do Ribeira, State of São Paulo, Brazil (collectors: Di Stasi, L. C., Reis, M. S. and Mariot, A.). Plant material used was Zollernia ilicifolia Vog. (Fabaceae) as authenticated by Dr. Ademir Reis, Herbario Barbosa Rodrigues, Itajaí, State of 
Santa Catarina, Brazil, where voucher specimens were deposited. Maytenus ilicifolia and M. aquifolium were obtained as previously described (Leite et al., 2001; Vilegas et al., 1999).

\section{Apparatus}

ES-MS was performed spectrometer on a Fisons VG Platform in positive $(70 \mathrm{~V})$ mode. The sample was dissolved in $\mathrm{MeOH}$ and injected directly.

IR spectrum was performed in a FT-IR-Nicolet Impact IMACT-400, KBr. The RMN spectra in DMSO $\mathrm{d}_{6}$ were obtained using a Varian INOVA 500 spectrometer, operating at $500 \mathrm{MHz}$ for ${ }^{1} \mathrm{H}$ and $125 \mathrm{MHz}$ for ${ }^{13} \mathrm{C}$ and $2 \mathrm{D}-\mathrm{NMR}\left({ }^{1} \mathrm{H}-{ }^{1} \mathrm{H}\right.$ COSY, HMQC, TOCSY, HMBC).

Preparative HPLC separations and analytical HPLC analyses were performed on a Varian ProStar 330 chromatograph (Sugar Land, Texas, USA) managed by a Varian workstation equipped with a Varian ProStar 220 diode array detector (DAD) operating from 200 a $600 \mathrm{~nm}$ and a Rheodyne injector with a $1 \mathrm{~mL}$ loop for preparative analyses and $20 \mu 1$ loop for analytical analyses. For the preparative analyses a Phenomenex column $\mathrm{C}_{18} 250 \mathrm{~mm} \times 10 \mathrm{~mm}$ was used at flow rate of $2 \mathrm{ml} /$ min using $\mathrm{MeOH} / \mathrm{H}_{2} \mathrm{O} 60: 40 \mathrm{v} / \mathrm{v}$ as eluent. For the analytical analyses the column used was a Phenomenex $\mathrm{C}_{18} 250 \times 4.6 \mathrm{~mm}$ i.d., at $30^{\circ} \mathrm{C}$. Gradient elution was performed starting from $\mathrm{MeOH} 20 \%$ until $\mathrm{MeOH} 100 \%$, during $30 \mathrm{~min}$, as mobile phase at a flow rate of $1.0 \mathrm{ml} / \mathrm{min}$. Monitoring wavelength were 205 and $254 \mathrm{~nm}$. The infusion was filtered on a $0.45 \mu \mathrm{m}$ Millex filter and directly injected. Standard solutions of compounds $\mathbf{1}$ and $\mathbf{2}$ and flavonoids isolated from $M$. ilicifolia (Leite et al., 2001) and M. aquifolium (Vilegas et al., 1999) were dissolved in the mobile phase and injected into the HPLC for qualitative purposes.

TLC analyses were carried out on silica gel $60 \mathrm{G}$ (Merck) $(20 \mathrm{~cm} \times 20 \mathrm{~cm} \times 0.2 \mathrm{~mm})$ plates eluted either with n-BuOH-AcOH- $\mathrm{H}_{2} \mathrm{O}$ 65:15:25 v/v/v or with $\mathrm{CHCl}_{3}-\mathrm{MeOH}-\mathrm{H}_{2} \mathrm{O}-\mathrm{n}-\mathrm{PrOH}$ (5:6:4:1 v/v/v), lower layer). The spots were visualized separatedly by spraying with NP/PEG reagent or $10 \%$ $\mathrm{H}_{2} \mathrm{SO}_{4}$ followed by heating at $110^{\circ} \mathrm{C}$ for $5 \mathrm{~min}$ (Wagner et al., 1984). Sephadex LH-20 (Pharmacia) was used for GPC.

\section{Preparation of infusions for qualitative HPLC} analysis

One gram of air-dried leaves of Zollernia ilicifolia, Maytenus aquifolium and Maytenus ilicifolia were separately milled and put into $50 \mathrm{ml}$ Erlenmeyer flasks. Boiled water $(10 \mathrm{ml})$ was added to each sample. The infusion was centrifuged, and the supernatant was filtered through a $0.45 \mu \mathrm{m}$ Millex filter. The filtered solution $(10 \mu \mathrm{l})$ was directly injected into the analytical HPLC system.

\section{Extraction and isolation of $\mathbf{1}$ and $\mathbf{2}$}

The fresh leaves of Zollernia ilicifolia were detached from the stems, dried in an oven at $37^{\circ} \mathrm{C}$ and powdered in a mill. The dried powder $(110 \mathrm{~g})$ was boiled for $8-9 \mathrm{~min}$ with water $(1.11)$. The mixture was allowed to cool, filtered through filter paper, and evaporated to dryness, affording $5 \mathrm{~g}$ of crude extract of plant. This extract was dissolved in 1.01 water and fractionated by XAD-2 resin CC $(30 \mathrm{~cm} \times 3 \mathrm{~cm})$ eluted with $1.51 \mathrm{H}_{2} \mathrm{O}$ fraction, followed by $500 \mathrm{ml}$ pure $\mathrm{MeOH}$ and finally with $300 \mathrm{ml}$ pure acetone. An aliquot $(2.0 \mathrm{~g})$ of the methanolic fraction was dissolved in $10 \mathrm{ml} \mathrm{MeOH}$ and fractionated by Sephadex LH-20 CC $(100 \mathrm{~cm} \times 3 \mathrm{~cm})$ eluted with $\mathrm{MeOH}$ at $0.5 \mathrm{ml} / \mathrm{min}$ flow rate. 108 fractions of $5 \mathrm{ml}$ were collected. The fractions were combined according to their behavior by TLC [silica gel plates, n-BuOH/HOAc/ $\mathrm{H}_{2} \mathrm{O}$ 60:15:30 v/v/v], was purified on reversed phase HPLC on a C-18 Phenomenex column (flow rate $=2 \mathrm{ml} / \mathrm{min}$ ). Fraction containing cyanogenic glycoside was purified using $\mathrm{MeOH} / \mathrm{H}_{2} \mathrm{O} 50: 50 \mathrm{v} / \mathrm{v}$ as the eluent to yield pure compound $\mathbf{1}$ (20 mg, $\mathrm{t}_{\mathrm{R}}=9 \mathrm{~min}$ ), identified by its spectral data compared to those already reported (Seigler, 1975), and the flavonoid was purified using $\mathrm{MeOH} / \mathrm{H}_{2} \mathrm{O}$ 60:40 as eluent to afford the compound 2 (15 $\mathrm{mg}$, $\left.\mathrm{t}_{\mathrm{R}}=14 \mathrm{~min}\right)$

\section{Compound 1}

$\mathrm{C}_{14} \mathrm{H}_{17} \mathrm{NO}_{7}, \mathrm{UV} \lambda \max (\mathrm{MeOH}): 217 \mathrm{~nm}$. IR (KBr): $3264 \mathrm{~cm}^{-1}(\mathrm{OH}), 2476 \mathrm{~cm}^{-1}(\mathrm{C} \equiv \mathrm{N})$. ES-MS $m / z$ (rel. int.) (70 V, positive ion): 316 $[\mathrm{M}+\mathrm{H}]^{+}(100), 154[\mathrm{M}-162+\mathrm{H}]^{+}(30) .{ }^{1} \mathrm{H}$ NMR $\left(\mathrm{DMSO} \mathrm{d}_{6}\right) \delta 5.90(\mathrm{~s}, \mathrm{H}-2), 6.92(\mathrm{dd}, J=1.5$ and $1.5 \mathrm{~Hz}, \mathrm{H}-4), 6.83$ (ddd, $J=8.0,1.5$ and $1.5 \mathrm{~Hz}$, H-6), 7.24 (dd, $J=8.0$ and $8.0 \mathrm{~Hz}, \mathrm{H}-7$ ), 6.96 (ddd, 
$J=8.0,1.5$ and $1.5 \mathrm{~Hz}, \mathrm{H}-8), 4.18(\mathrm{~d}, J=8.5 \mathrm{~Hz}$, $\mathrm{H}-1$ glucose). $\alpha_{[\mathrm{D}]}=-28.5$.

\section{Compound 2}

$\mathrm{C}_{39} \mathrm{H}_{50} \mathrm{O}_{23}$, UV $\lambda \max (\mathrm{MeOH}): 264,346$. IR (KBr): $3378(\mathrm{OH}), 1650 \mathrm{~cm}^{-1}(\mathrm{C}=\mathrm{O})$. ES-MS $\mathrm{m} / z$ (rel. int.) $\left(70 \mathrm{~V}\right.$, positive ion): $887[\mathrm{M}+\mathrm{H}]^{+}(49)$, $287[\mathrm{~A}+\mathrm{H}]^{+}(100), 741[\mathrm{M}-146+\mathrm{H}]^{+}(29), 595$ $[\mathrm{M}-146-146+\mathrm{H}]^{+} \quad(34), \quad 431 \quad[\mathrm{M}-146-146-146-$ $\left.\mathrm{H}_{2} \mathrm{O}+\mathrm{H}\right]^{+}$(84). For ${ }^{1} \mathrm{H}$ and ${ }^{13} \mathrm{C}$ NMR data see Table I.

\section{Acid Hydrolysis of Compound $\mathbf{2}$}

A solution of compound $(3 \mathrm{mg})$ in $6 \% \mathrm{HCl}$ $(3.5 \mathrm{ml})$ was refluxed for $2 \mathrm{~h}$. The reaction mixture was diluted with $\mathrm{H}_{2} \mathrm{O}$ and then extracted with EtOAc. The resulting products were identified by TLC comparison according to their $\mathrm{R}_{\mathrm{f}}$ and also to their ${ }^{1} \mathrm{H}$ NMR spectra.

\section{Results and Discussion}

The infusion from the leaves of Zollernia ilicifolia was prepared as described in the Materials and Methods and was first submitted to $\mathrm{CC}$ on Amberlite XAD-2 resin and eluted with $\mathrm{H}_{2} \mathrm{O}$, $\mathrm{MeOH}$ and acetone, respectively. Chromatographic work up by GPC (gel permeation chromatography) followed by reversed-phase HPLC yield the known cyanogenic glycoside $\mathbf{1}$ and the new flavonoid 2.

Compound $\mathbf{2}$ was obtained as a yellow solid and showed a bright yellow spot on TLC observed in UV light after being sprayed with NP/PEG (natural products-polyethylene glycol) reagent, thus indicating a kaempferol derivative (Wagner et al., 1984). Acid hydrolysis of 2 released kaempferol, L-rhamnose and D-galactose, identified by TLC compared to authentic samples. The IR spectrum showed a strong absorption at $1650 \mathrm{~cm}^{-1}(\mathrm{C}=\mathrm{O})$ and a broad band at $3378\left(v_{\mathrm{OH}}\right)$. The UV spectrum was obtained through the HPLC-DAD analysis and presented bands at $264 \mathrm{~nm}$ and $346 \mathrm{~nm}$, showing good correlation to those of a kaempferol derivative (Mabry et al., 1970).

The ES-MS (70 V, positive ion) mass spectrum gave as base peak the $[\mathrm{M}+\mathrm{H}]^{+}$ion at $\mathrm{m} / \mathrm{z} 887$ (49\%), corresponding to the molecular formula $\mathrm{C}_{39} \mathrm{H}_{50} \mathrm{O}_{23}$. The fragment at $\mathrm{m} / \mathrm{z} 287(100 \%)$ cor- responds to the protonated aglycone $[\mathrm{A}+\mathrm{H}]^{+}$, thus reinforcing that compound $\mathbf{2}$ is a kaempferol derivative. Fragment ions at $\mathrm{m} / z$ $741[\mathrm{M}-146+\mathrm{H}]^{+}$ $(29 \%)$, at $m / z 595[\mathrm{M}-146-146+\mathrm{H}]^{+}(34 \%)$ and at $m / z 431\left[\mathrm{M}-146-146-146-\mathrm{H}_{2} \mathrm{O}+\mathrm{H}\right]^{+}(15 \%)$, correspond to independent losses of terminal deoxyhexose units.

The complete structure of 2 was elucidated by 1D and 2D-NMR experiments at $500 \mathrm{MHz}$. The ${ }^{1} \mathrm{H}$ NMR spectra (Table I) displayed signals for two meta-coupled protons at $\delta 6.44(d, J=2.0 \mathrm{~Hz}, 1 \mathrm{H})$ and $\delta 6.79(d, J=2.0 \mathrm{~Hz}, 1 \mathrm{H})$ corresponding to H6 and H8, respectively (Harborne et al., 1996). An ortho-coupled system at $\delta 8.02(d, J=8.5 \mathrm{~Hz}$, $2 \mathrm{H})$ and $\delta 6.87(d, J=8.5 \mathrm{~Hz}, 2 \mathrm{H})$ corresponds to $\mathrm{H} 2^{\prime} / \mathrm{H} 6^{\prime}$ and $\mathrm{H} 3^{\prime} / \mathrm{H} 5^{\prime}$, respectively, and confirmed the structure of a kaempferol derivative (Harborne et al., 1996). The ${ }^{13} \mathrm{C}$ NMR spectrum showed 39 signals, 15 from which could be assigned to the kaempferol aglycone (Harborne et al., 1996; Agrawal, 1989) (Table I).

The presence of four anomeric signals at $\delta 5.58$ $(d, J=8.0 \mathrm{~Hz}), \delta 5.55(d, J=1.5 \mathrm{~Hz}), \delta 5.05(d$, $J=1.5 \mathrm{~Hz})$ and $\delta 4.37(d, J=1.5 \mathrm{~Hz})$ in the ${ }^{1} \mathrm{H}$ NMR spectra and four anomeric carbons at $\delta$ 100.5, 99.9, 98.9 and 98.4 in the ${ }^{13} \mathrm{C}$ NMR spectra suggested 2 to be a tetrasaccharide (Table I). Furthermore, the presence of doublets with $J=$ $7 \mathrm{~Hz}$ at $\delta 0.79, \delta 1.05, \delta 1.13$ in the ${ }^{1} \mathrm{H}-\mathrm{NMR}$ spectrum and at $\delta 17.2, \delta 17.6$ and $\delta 17.8$ in the ${ }^{13} \mathrm{C}$ NMR spectrum indicated the presence of three rhamnose moieties.

To determine the nature of the monosaccharides, the sequences of the oligosaccharide chain and the site of attachment to the kaempferol skeleton we performed DFQ-COSY, 1D-TOCSY, $\mathrm{HMBC}$ and HMQC experiments. Analysis of the DFQ-COSY spectrum combined with the TOCSY data secured the assignments of the spin systems for each sugar moiety of the tetraglycoside moiety of $\mathbf{2}$ as presented in Table I. Irradiation of the anomeric signals of the rhamnose unities led to the observation of the H1-H2 spin system, whereas irradiation over the anomeric signal of the galactose moiety led to the observation of signals corresponding to $\mathrm{H} 1$ to $\mathrm{H} 4$.

The HMQC experiment allowed to establish the direct ${ }^{1} \mathrm{H}_{-}{ }^{13} \mathrm{C}$ correlations (Table I), while the connecting position of the sugars were established using HMBC experiments. Correlations were ob- 
Table I. ${ }^{1} \mathrm{H}$ NMR and ${ }^{13} \mathrm{C}$ NMR spectral data for 2 (in DMSO d 6 6, $500 \mathrm{MHz})$.

\begin{tabular}{|c|c|c|}
\hline Position & $\delta{ }^{13} \mathrm{C}$ & $\delta{ }^{1} \mathrm{H}$ \\
\hline 2 & 155.9 & - \\
\hline 3 & 132.9 & - \\
\hline 4 & 177.6 & - \\
\hline 5 & 161.6 & - \\
\hline 6 & 99.3 & $6.44(\mathrm{~d}, 2.0)$ \\
\hline 7 & 160.8 & - \\
\hline 8 & 94.5 & $6.79(\mathrm{~d}, 2.0)$ \\
\hline 9 & 156.8 & - \\
\hline 10 & 105.5 & - \\
\hline $1^{\prime}$ & 120.6 & - \\
\hline $2^{\prime}, 6^{\prime}$ & 130.9 & $8.09(\mathrm{~d}, 8.5)$ \\
\hline $3^{\prime}, 5^{\prime}$ & 115.0 & $6.87(\mathrm{~d}, 9.0)$ \\
\hline $4^{\prime}$ & 160.0 & $8.09(\mathrm{~d}, 8.5)$ \\
\hline 3-Gal & & - \\
\hline 1 & 98.9 & $5.58(\mathrm{~d}, 8.0)$ \\
\hline 2 & 74.9 & - \\
\hline 3 & 73.7 & - \\
\hline 4 & 68.1 & - \\
\hline 5 & 73.3 & - \\
\hline \multirow[t]{2}{*}{6} & 65.0 & - \\
\hline & & - \\
\hline$(2-1)$ Rha & & - \\
\hline 1 & 100.5 & $5.05(\mathrm{~d}, 1.5)$ \\
\hline 2 & 70.6 & - \\
\hline 3 & 70.5 & - \\
\hline 4 & 71.5 & - \\
\hline 5 & 71.5 & - \\
\hline 6 & 17.2 & $0.79(\mathrm{~d}, 6.5)$ \\
\hline \multicolumn{3}{|l|}{$(6-1)$ Rha } \\
\hline 1 & 99.9 & $4.37(\mathrm{~d}, 1.5)$ \\
\hline 2 & 70.5 & - \\
\hline 3 & 70.2 & - \\
\hline 4 & 71.8 & - \\
\hline 5 & 71.8 & - \\
\hline 6 & 17.8 & $1.05(\mathrm{~d}, 6,0)$ \\
\hline \multicolumn{3}{|l|}{ 7-Rha } \\
\hline 1 & 98.4 & $5.55(\mathrm{~d}, 1.5)$ \\
\hline 2 & 70.0 & - \\
\hline 3 & 70.3 & - \\
\hline 4 & 71.8 & - \\
\hline 5 & 69.8 & - \\
\hline 6 & 17.8 & $1.13(\mathrm{~d}, 6.0)$ \\
\hline
\end{tabular}

served between the anomeric signal of galactose $(\delta 5.58, d, J=8.0 \mathrm{~Hz}$ ) and the $\mathrm{C}-3$ of the kaempferol ( $\delta 132.9)$, the anomeric hydrogen signal of the inner rhamnose $(\delta 5.05, d, J=1.5 \mathrm{~Hz})$ and the $\mathrm{C}-2$ of galactose ( $\delta 74.9$ ), the anomeric hydrogen of the outer rhamnose $(\delta 4.37, d, J=1.5 \mathrm{~Hz})$ and the C-6 of the galactose $(\delta 65.0)$. Additional correlation was observed between the hydrogen anomeric of the third rhamnose moiety $(\delta 5.55, d, J=$ $1.5 \mathrm{~Hz}$ ) and the C-7 of kaempferol ( $\delta$ 160.8).
The $\beta$-configuration at the anomeric position for the galactopyranosyl unity $\left(J_{\mathrm{H} 1-\mathrm{H} 2}=8.0 \mathrm{~Hz}\right)$ was easily seen from their relatively large ${ }^{3} J_{\mathrm{H} 1-\mathrm{H} 2}$ coupling constants $(7-8 \mathrm{~Hz})$. The $\alpha$-configuration in the rhamnose residues was clear from their $\mathrm{H}-1$ non-splitting pattern and their distinct C-3 and C-5 chemical shift differences from that of methyl $\beta-\mathrm{L}-$ rhamnopyranoside (Agrawal, 1989).

These findings indicated that the structure of compound $\mathbf{2}$ is the new kaempferol-3-O- $\alpha-\mathrm{L}-$ rhamnopyranosyl $(1 \rightarrow 2)$-O-[ $\alpha$-L-rhamnopyranosyl$(1 \rightarrow 6)]$-O- $\beta$-D-galactopyranosyl-7-O- $\alpha$-L-rhamnopyranoside (Fig. 1).

A quercetin tetraglycoside with a similar sugar chain was previously isolated from the leaves of Rhazya stricta (Apocynaceaae) (Andersen et al., 1987). Few other studies report the isolation of flavonoid tetraglycosides in plants. Vilegas et al. (1999) identified the presence of kaempferol 3-O$\alpha$-L-rhamnopyranosyl $(1 \rightarrow 6)-O$ - $[\beta$-D-glucopyrano$\operatorname{syl}(1 \rightarrow 3)-O$ - $\alpha$-L-rhamnospyranosyl $(1 \rightarrow 2)-O-\beta$-Dgalactopyranoside and quercetin 3- $O$ - $\alpha$-L-rhamnopyranosyl $(1 \rightarrow 6)-O$ - $[\beta$-D-glucopyranosyl $(1 \rightarrow 3)-O$ $\alpha$-L-rhamnospyranosyl $(1 \rightarrow 2)$ - $O$ - $\beta$-D-galactopyranoside in the infusion of the leaves from Maytenus aquifolium that presented significant anti-ulcer activity (Vilegas et al., 1999). Therefore, the observed anti-ulcer activity of the $\mathrm{MeOH} 70 \%$ extract of $Z$. ilicifolia could be related to the presence of the flavonoid tetraglucoside $\mathbf{2}$, since the structures are similar to those found in species of Maytenus, plants with analgesic and antiulcerogenic effects. Further studies are in progress to check this hypothesis and to identify the analgesic and antiulcerogenic mechanisms of actions.

The main objective of this study was to investigate the chemical compounds from Zollernia ilicifolia because this species is used as a herbal remedy in traditional medicine of the Brazilian tropical Atlantic Forest Region, State of São Paulo, Brazil (Di Stasi et al., 2001). However, previous pharmacological tests have also shown that animals treated with Z. ilicifolia extract exhibited increase of irritability and respiratory rate, loss of corneal reflex and decrease of motor activity (Gonzalez et al., 2001). Although the cyanogenic glycoside was not pharmacologically evaluated, the presence of this compound in the infusion is an alert against a possible misuse of this species as medicinal plant or instead of the true 'espinheiras-santas'. 
<smiles>O=c1c(O)c(-c2ccc(O)c([Al])c2)oc2cc(O)cc(O)c12</smiles>

\begin{tabular}{lcccc} 
& & R1 & Sugar sequence $(\mathbf{R 2})$ & $\mathbf{R}_{\mathbf{t}}[\mathbf{m i n}]$ \\
\hline Zollernia ilicifolia & $\mathbf{2}$ & $\mathrm{H}$ & 3-[-Rha $(1 \rightarrow 6) \mathrm{Rha}(1 \rightarrow 2) \mathrm{Gal}], 7-\mathrm{Rha}$ & 17.6 \\
Maytenus aquifolium & $\mathbf{3}$ & $\mathrm{H}$ & 3-Rha $(1 \rightarrow 6) \mathrm{Glu}(1 \rightarrow 3) \mathrm{Rha}(1 \rightarrow 2) \mathrm{Gal}$ & 18.9 \\
& $\mathbf{4}$ & $\mathrm{OH}$ & 3-Rha $(1 \rightarrow 6) \mathrm{Glu}(1 \rightarrow 3) \mathrm{Rha}(1 \rightarrow 2) \mathrm{Gal}$ & 21.8 \\
Maytenus ilicifolia & $\mathbf{5}$ & $\mathrm{H}$ & 3-Rha $(1 \rightarrow 6) \mathrm{Ara}(1 \rightarrow 3) \mathrm{Rha}(1 \rightarrow 2) \mathrm{Gal}$ & 19.2
\end{tabular}

Fig. 1. Flavonoid tetraglycosides isolated from Zollernia ilicifolia, Maytenus aquifolium and Maytenus ilicifolia leaves: kaempferol-3-O- $\alpha$-L-rhamnopyranosyl $(1 \rightarrow 2)-\mathrm{O}-[\alpha-\mathrm{L}$-rhamnopyranosyl $(1 \rightarrow 6)]-\mathrm{O}-\beta$-D-galactopyranoside-7-O$\alpha$-L-rhamnopyranoside 2 , kaempferol 3- $O$ - $\alpha$-L-rhamnopyranosyl $(1 \rightarrow 6)-O$ - $[\beta$-D-glucopyranosyl $(1 \rightarrow 3)$ - $O$ - $\alpha$-L-rhamnospyranosyl $(1 \rightarrow 2)$ - $O$ - $\beta$-D-galactopyranoside $\mathbf{3}$, quercetin 3 - $O$ - $\alpha$-L-rhamnopyranosyl $(1 \rightarrow 6)$ - $O$ - $[\beta$-D-glucopyrano$\operatorname{syl}(1 \rightarrow 3)-O$ - $\alpha$-L-rhamnospyranosyl $(1 \rightarrow 2)-O$ - $\beta$-D-galactopyranoside $\mathbf{4}$, and kaempferol 3-O- $\alpha$-L-rhamnopyrano$\operatorname{syl}(1 \rightarrow 6)$ - $O$-[ $\alpha$-L-arabinopyranosyl $(1 \rightarrow 3)-O$ - $\alpha$-L-rhamnospyranosyl $(1 \rightarrow 2)-O$ - $\beta$-D-galactopyranoside 5 .

Therefore, to check the chemical differences between the infusions of Zollernia ilicifolia and of the true 'espinheiras-santas' (Maytenus aquifolium and Maytenus ilicifolia) we developed a method based on the comparative HPLC-DAD analysis.

The chromatography profiles of the infusions could be established by comparing the retention times and UV spectra of the peaks with those of isolated compounds from Zollernia ilicifolia and Maytenus species (Fig. 1).

Concerning flavonoidic compounds, checked by their UV spectra, the three infusions show peaks in a narrow range of retention time, between $17.6 \mathrm{~min}$ and $21.8 \mathrm{~min}$. These small differences probably arises from the different sugar moieties attached to the aglycones, but these flavonoids are useful markers to differenciate each infusion.

The chromatogram of the infusion of Zollernia ilicifolia at $205 \mathrm{~nm}$ shows an additional intense peak due to the cyanogenic glycoside $(S)$ - zierin
$1\left(t_{R}=9 \mathrm{~min}\right)$, absent in the infusion of the Maytenus species.

Therefore, not only the presence of the flavonoids but also of the cyanogenic glycoside $\mathbf{1}$ can be used to establish chemical differentiation between the infusions of Maytenus species and the false espinheira-santa Zollernia ilicifolia affording valuable chemical markers for the assessment of the quality control of these plants as phytomedicines.

\section{Acknowledgments}

The authors thank Nivaldo Boralle from Instituto de Quimica de Araraquara for recording the NMR spectra, to Fundação de Amparo a Pesquisa do Estado de São Paulo - FAPESP for supporting part of this work, for a fellowship to R. G. C. and for a grant to L. C. D. S. and to Conselho Nacional de Desenvolvimento Cientifico e Tecnológico CNPq, for a grant to W. V. 
Andersen W. K., Omar A. A. and Christensen S. B. (1987), Isorhamnetin 3-(2,6-dirhamnopyranosylgalactoside)-7-rhamnoside and 3-(6-rhamnopyranosylgalatoside)-7-rhamnoside from Rhazya stricta. Phytochemistry 26, 291-294.

Agrawal P. K.(1989), Carbon-13 NMR of Flavonoids. Elsevier, Amsterdam, NL.

Di Stasi L. C., Oliveira G. P., Carvalhaes M. A., QueirozJunior M., Tien O. S., Kakinami S. H. and Reis M. S. (2002), Medicinal plants popularly used in the Brazilian tropical atlantic forest. Fitoterapia. 73, 69-91.

Ferrari F., Botta B. and Alves de Lima R. (1983), Flavonoids and isoflavonoids from Zollernia paraensis. Phytochemistry 2, 1663-1664.

Ferrari F., Botta B., Alves de Lima R. and Betollo G. B. M. (1984), 2,4,2'-Trihydroxy-4'-methoxybenzene from Zollernia paraensis. Phytochemistry 23, 26912692.

Gonzalez F. G., Portela T. Y., Stipp E. J. and Di Stasi, L. C. (2001), Antiulcerogenic and analgesic effects of the three Maytenus ilicifolia ("espinheira-santa") adulterants: Maytenus aquifolium, Sorocea bomplandii and Zollernia ilicifolia. J. Ethnopharmacol. 77, $41-47$.

Harborne J. B. (1996), The Flavonoids. Advances in Research Since 1986. Chapman and Hall, London, England.

Leite J. P. V., Rastrelli L., Romussi G., Oliveira A. B., Vilegas J. H. Y. V., Vilegas W. and Pizza, C. (2001),
Isolation and HPLC quantitative analysis of flavonoid glycosides from Brazilian beverages (Maytenus ilicifolia and M. aquifolium). J. Agric. Food Chem. 49, 3796-3801.

Mabry T. J., Markham K. R. and Thomas M. B. (1970), The Systematic Identification of Flavonoids. Springer, New York, USA.

Sanommiya M., Vilegas W., Rastrelli L. and Pizza C. (1998), Flavonoid glycoside from Maytenus aquifolium. Phytochemistry 54, 237-239.

Seigler D. S. (1975), Isolation and characterization of naturally occurring cyanogenic compounds. Phytochemistry 14, 9-29.

Souza-Formigoni M. L. O., Oliveira M. G. M., Monteiro M. G., Filho N. G. S., Braz S. and Carlini E. A. (1991), Antiulcerogenic effects of two Maytenus species in laboratory animals. J. Ethnopharmacol. 34, 21-27.

Vilegas J. H. I., Lanças F. M. and Antoniosi, N. R. (1995), High temperature capillary GC analysis of phytopreparations of espinheira-santa (Maytenus ilicifolia and Maytenus aquifolium-Celastraceae), a Brazilian antiulcer plant. Chromatographia 40, 341-344. Vilegas W., Sanommiya M., Rastrelli L. and Pizza, C. (1999), Isolation and structure of two new flavonoid glycoside from the infusion of Maytenus aquifolium leaves. Evaluation of the antiulcer activity of the infusion. J. Agric. Food Chem. 47, 403-406.

Wagner H., Bladt S. and Zgainski E. M. (1984), Plant Drug Analysis. Springer, Berlin, Germany. 